\title{
BMJ Open Prevalence of mental ill health, traumas and postmigration stress among refugees from Syria resettled in Sweden after 2011: a population-based survey
}

\author{
Petter Tinghög, ${ }^{1,2}$ Andreas Malm, ${ }^{1,2,3}$ Charlotta Arwidson, ${ }^{1}$ Erika Sigvardsdotter, ${ }^{1}$
} Andreas Lundin, ${ }^{4}$ Fredrik Saboonchi ${ }^{1,2}$

To cite: Tinghög P, Malm A, Arwidson C, et al. Prevalence of mental ill health, traumas and postmigration stress among refugees from Syria resettled in Sweden after 2011: a populationbased survey. BMJ Open 2017;7:e018899. doi:10.1136/ bmjopen-2017-018899

- Prepublication history and additional material for this paper are available online. To view these files, please visit the journal online (http://dx.doi. org/10.1136/bmjopen-2017018899).

Received 28 July 2017 Revised 21 November 2017 Accepted 28 November 2017

\section{CrossMark}

${ }^{1}$ Department of Health Sciences, Red Cross University College, Stockholm, Sweden

${ }^{2}$ Division of Insurance Medicine, Department of Clinical Neuroscience, Karolinska Institutet, Stockholm, Sweden

${ }^{3}$ The Swedish Red Cross Treatment Center for Persons Affected by War and Torture, Malmö, Sweden

${ }^{4}$ Department of Public Health Sciences, Karolinska Institutet, Stockholm, Sweden

Correspondence to Dr Petter Tinghög; petter.tinghog@rkh.se

\section{ABSTRACT}

Objectives To estimate the prevalence of and associations between anxiety, depression, post-traumatic stress disorder (PTSD), low subjective well-being (SWB), potential traumas and postmigration stress among refugees from Syria resettled in Sweden.

Design A cross-sectional and population-based questionnaire study based on a known and complete sample frame. The survey included multiple measures of mental ill health and factors of particular relevance for refugees. Weighted analyses were conducted to calculate representative prevalence rates and associations.

Associations were investigated through a series of logistic regression analyses. All analyses were supplemented with robust $95 \%$ Cls.

Setting Sweden.

Participants A random sample of 1215 individuals (response rate 30.4\%) from Syria aged 18-64 years that were granted residency in Sweden on grounds of asylum between 2011 and 2013.

Main outcome measures Anxiety, depression, PTSD and low SWB were assessed through Hopkins Symptom Checklist, Harvard Trauma Questionnaire and WHO-5 Wellbeing Index, using established cut-offs.

Results A majority of the participants met the criteria for at least one of the studied types of mental ill health, and the comorbidity was high. Depression was the most the common type with $40.2 \%(95 \% \mathrm{Cl} 36.9 \%$ to $43.3 \%)$, followed by low SWB with $37.7 \%(95 \% \mathrm{Cl}$ $34.8 \%$ to $40.1 \%)$, anxiety with $31.8 \%(95 \% \mathrm{Cl} 29.2 \%$ to $34.7 \%$ ) and PTSD with $29.9 \%$ (95\% Cl $27.2 \%$ to $32.6 \%$ ). Refugee-related potentially traumatic events (PTEs) experienced before or during migration was common as was substantial levels of postmigration stress. Most types of refugee-related PTEs, especially being exposed to interpersonal violence, and postmigration stress were associated with increased risks for anxiety, depression, low SWB and PTSD.

Conclusions Mental ill health, in terms of anxiety, depression, low SWB and PTSD, are highly elevated and comorbid among refugees from Syria. Increased attention from multiple societal sectors to adequately support Syrian refugees' mental health needs, promoting recovery and reducing postmigration stress are needed.
Strengths and limitations of this study

- This is the first larger comprehensive study of mental ill health among recently resettled refugees from Syria in a European country.

- The non-response rate is substantial, but the availability of register-based information for all eligible study participants enabled construction of non-response weights to obtain reliable estimates.

- The robustness of the study findings are supported by a series of sensitivity analyses.

- Several measures were taken, such as a doubleblind translation and back-translation procedure and cognitive interviewing to ensure that the questionnaire was appropriate and valid for the target population.

- The analyses are based on cross-sectional data, which typically make causal claims on the basis of temporality ambiguous variables problematic.

\section{INTRODUCTION}

The war in Syria has since it started in 2011 been responsible for almost half a million deaths. ${ }^{1}$ Additionally, more than 11 million individuals have been forced to leave their homes, and of these, around one million individuals have reached Europe. ${ }^{2}$ Sweden has received more than 100000 asylum seekers from Syria since 2011, ${ }^{2}$ making Sweden the second largest European recipient of refugees from Syria. However, reliable prevalence rates of mental ill health and stressful or traumatising experiences in this refugee population is still lacking. A clearer picture based on robust empirical data of the magnitude of mental ill health among Syrian refugees resettled in Europe and to what extent they have been exposed to known risk factors are imperative to adequately address their mental health needs on a societal level.

The estimated prevalence of post-traumatic stress disorder (PTSD), anxiety disorders and depression in refugee populations are known 
to vary extensively between studies and populations. In a review article including 29 studies on long-term mental health among war affected refugees, Bogic et $a \hat{l}$ reported prevalence rates ranging from $4.4 \%$ to $86 \%$ for PTSD, from $2.3 \%$ to $80 \%$ for depression and from $20.3 \%$ to $88 \%$ for anxiety. This type of heterogeneity has also been observed in Fazal et al's $s^{4}$ systematic review based on studies using psychiatric interviews to assess mental disorders among refugees resettled in western countries. Such disparate rates are of course of little use for estimating how common mental ill health is among Syrian refugees in Europe today. They nonetheless illustrate the problem of regarding groups of refugees as homogenous populations. A plethora of circumstances including differences in premigration experiences, support and reception in the resettlement country and immigration laws make extrapolations from one refugee population to another hazardous, and even if such extrapolations in certain cases might appear reasonable, available studies are generally based on fairly small convenience samples, and the sociodemographic distribution of the sample frames are usually unknown, ${ }^{3}$ making it difficult to evaluate the validity of the obtained estimates.

Often when studying refugees' mental ill health, a distinction is made between risk factors encountered before or after the migration. ${ }^{5}$ Refugee-related, or war-related, potentially traumatic events (PTEs) are the type of premigratory risk factors that has been given most attention in the literature, and many of them have also been shown to be strongly associated with mental ill health. ${ }^{6}$ Associations of this kind have been observed in many refugee populations and at many different resettlement destinations including Europe. ${ }^{78}$ In particular, experiences of interpersonal violence during the premigration phase have been linked to mental health problems. ${ }^{9}$ Even though these types of associations are usually stronger in relation to PTSD, they have commonly also been observed when employing anxiety and depression as outcomes measures. ${ }^{1011}$ What is however seldom taken into account when studying refugees' mental health is the that the flight in itself may also be difficult and contain additional severe traumatic events. ${ }^{12}$

During the postmigration phase, refugees (as well as non-refugee migrants) may experience a host of different types of difficulties that can hamper recovery, increase mental ill health or be instrumental for the development of mental ill health. ${ }^{5}$ These types of experiences are often referred to as postmigration stress and are typically of a more persistent character than PTEs that tend to be sudden and/or traumatic. Studies have indicated that postmigration experiences in many circumstances tend to be more detrimental to refugees' mental health than PTEs and that PTEs are associated with postmigration stress (see further, eg, ref 5 ). Several types of postmigration stressful experiences have been identified as being especially common among migrant/refugee populations. These have been shown to be associated with mental ill health: intergenerational and spousal conflicts, ${ }^{1314}$ ethnic discrimination, ${ }^{15}$ harsh socioeconomical living conditions, ${ }^{16-19}$ loss of status, ${ }^{717}$ institutional accommodation, ${ }^{20}$ poor language skills ${ }^{1619}$ and poor social support. ${ }^{71719}$

In this study, we aim to estimate prevalence of anxiety, depression, PTSD, low subjective well-being (SWB), different refugee-related PTEs and different postmigration stressful experiences and explore mental ill health comorbidity among recently resettled refugees from Syria in Sweden. Furthermore, our aim is to investigate if different types of refugee-related PTEs and different types postmigration stressful experiences are associated with mental ill health among recently resettled refugees from Syria, as findings from other contexts would indicate.

\section{METHODS \\ Participants}

The study population consist of a random sample of 1215 individuals from Syria aged 18-64 years who were granted permanent residency in Sweden on grounds of asylum between 2011 and 2013. The sampling frame was the Total Population Register (TPR) maintained by the government agency Statistics Sweden, containing addresses as well as data on vital status including birth and death years, birth country, educational level and marital status. TPR is a nationwide register covering all individuals with permanent residency. Information on grounds for residency were obtained from the STATIV database, which is a database containing migration-related information for individuals who have applied for residency.

\section{Procedure}

Before launching the study, a reference group of Syrian refugees with expertise in mental health research, healthcare and/or Arabic language was set up. The group was consulted on cultural aspects of mental ill health, appropriate data collection methods and language issues. Their input informed the implementation of the study and the construction of the questionnaire. The reference group also assisted in a social media campaign to explain the study's purpose to the target population and served as Arabic speaking contact persons for those invited to the survey.

In 2016, a postal questionnaire in Arabic was distributed to a random sample of 4000 refugees from Syria meeting the inclusion criteria, of which $30.4 \% \quad(n=1215)$ chose to participate (the non-response analysis is presented in the results section). Given that the sample frame included 9662 individuals, a minimum of 1000 respondents were deemed adequate, as the sample size then would consist of more than $10 \%$ of the individuals included in the total sample frame. The questionnaire included scales and items to measure mental ill health and factors hypothesised to be of particular relevance for refugees' mental health and socioeconomic integration.

A standard double-blind translation and back-translation procedure was used unless adapted Arabic versions of specific parts of the questionnaire already were available. 
The entire questionnaire was, however, discussed with community experts in focus groups and individually throughout the translation and adaptation process. Revisions and amendments were done in consensus when such changes were deemed necessary.

Usability of the questionnaire was tested by conducting interviews in a rehabilitation centre for war and torture trauma patients, with 10 patients with Arabic as their mother tongue. The interviewees were instructed to read the questions out loud and to follow a Think-Aloud Protocol (TAP). TAP is a method designed to provide information about difficulties that may arise due to problems with comprehension, memory retrieval, judgement and response formatting. ${ }^{21}$ On any indication of such difficulties, the target item was further scrutinised by the research group, language and community experts and by examining the psychometrics profile of the item from data compiled from a small pilot study and was thereafter modified if needed.

\section{MEASURES}

\section{Sociodemographic factors}

All sociodemographic data used in this study were retrieved from Statistics Sweden's nationwide database TPR. Age was categorised into the following four age groups: 18-29 years, 30-39 years, 40-49 years and 50-64 years; educational level was categorised as: 0-9 years, $>9$ years without a university degree and $>12$ years with a university degree; marital status was categorised as: married, unmarried and divorced/widow/widower; and year of immigration was categorised as $\geq 2011$ (ie, 5 years or more since immigration), 2012 and 2013. This information, except marital status, were also obtained for the non-respondents for the purpose of constructing non-response weights.

\section{Refugee-related potentially traumatic premigration and perimigration events}

To identify respondents that had been exposed to refugee-related PTEs before arriving to Sweden, two (identical) checklists were developed to cover the premigration and perimigration periods separately ${ }^{22}$ (the perimigration period does in this context refer to the period between leaving the home in Syria and arriving to Sweden). The checklists aim to measure PTEs related to the refugee experience in a non-intrusive manner while simultaneously trying to encapsulate the most common types of refugee-related PTEs that have been reported in the scientific literature. In the present study, the two checklists have been combined. An assessment is thus made of whether the respondents have been exposed to the following eight types refugee-related PTEs before arriving to Sweden: war at close quarters (ie, close proximity to war combat), forced separation from family or close friends, loss or disappearance of family member(s) or loved one(s), physical violence or assault, witnessing physical violence or assault, torture, sexual violence, other frightening situations where you felt your life was in danger.

\section{Postmigration stress}

We constructed seven domains of postmigration stress that encircled relevant and common experiences found when reviewing the literature or reported by Red Cross patients with refugee status. The seven single item questions used in this study are intended to tap into these separate domains, that is, item: felt disrespected due to national background (domain: perceived discrimination), bothering difficulties communicating in Swedish (lack of host country specific competencies), unable to buy necessities (economic strain), missing social life from back home (loss of home country), sad because not reunited with family members (home country and family concerns), felt excluded or isolated in the Swedish society (social strains) and distressing conflicts in family (family conflicts). The respondents were requested to indicate how frequently he or she had experienced these specific situations, on a 5-point Likert scale ranging from 'never' to 'very often', since arriving to Sweden. Those responding 'often' or 'very often' were classified as having had these types of experiences often after resettlement in Sweden.

\section{Mental ill health measures}

Hopkins Symptom Checklist (HSCL-25), Harvard Trauma Questionnaire (HTQ) and WHO-5 Well-being Index (WHO-5) were employed to estimate different manifestations of mental ill health, that is, anxiety, depression, PTSD and low SWB. These scales have been frequently used among refugees and in population-based surveys and been shown to possess sound psychometric properties among Arabic speakers. ${ }^{23} 24$

HSCL-25 consists of 10 anxiety and 15 depression items. The items, which refer to how specific symptoms have bothered or distressed the individual during the last week, have four response alternatives ranging from 'not at all' (1) to 'very much' (4). Individual mean item scores were calculated separately for the anxiety and depression subscales. Respondents with a mean item score above 1.80 and 1.75 were classified as having depression or anxiety, respectively. ${ }^{25}{ }^{26}$ Cronbach's alpha for the depression and the anxiety scales was 0.93 and 0.92 , respectively.

In HTQ the first 16 symptoms from section IV were used to identify individuals with PTSD. ${ }^{25}$ This part of HTQ has a similar structure as the HSCL-25, in that it uses the same response format, referring to the same time frame, and mean item scores are calculated. In the present study, we used the mean item score of 2.06 to distinguish cases of PTSD from non-cases. ${ }^{25}$ Cronbach's alpha was 0.92 .

WHO-5 was used as a global measure of subjective wellbeing. WHO-5 contains five statements of the type 'I have felt happy and in a good mood' and the response alternatives range from 'all the time' (5) to 'never' ( 0 ) in relation to the last 2 weeks. The highest possible value of that scale is 100 , as the total score is multiplied by a factor of 
four. Those with values below 50 are classified as having low SWB. ${ }^{27}$ Cronbach's alpha was 0.94 .

\section{Statistical analysis}

As the sample was not entirely representative with regards to sociodemographic factors, inverse probability (or non-response) weights were constructed using logistic regression. These weights were based on the main effects of gender, age groups, educational level and year of immigration and the interaction effect between gender and age groups, as this was the only two-way interaction that significantly predicted study participation $(\mathrm{P}<0.05)$ in univariate analyses. All presented analyses are based on weighed data unless otherwise stated. The following analyses were thereafter conducted.

First, the sociodemographic distribution of the sample, the sample frame and the weighted sample were calculated and presented in percentages.

Second, prevalence estimates for anxiety, depression, low SWB and PTSD were calculated for the total population and for sociodemographic subpopulations.

Third, proportions with mental ill health comorbidities and binominal correlations between the four used measures of mental ill health were estimated.

Fourth, prevalence of refugee-related PTEs and postmigration stress were calculated. A series of logistic regression analyses were, thereafter, conducted to explore the association between these factors and the four studied measures of mental ill health. All these analyses were adjusted for sociodemographic factors. Furthermore, associations between types of postmigration stress and mental ill health were adjusted for the eight refugee-related PTEs, number of PTEs and number of PTEs squared. Postmigration stress factors were, however, not adjusted for when examining the associations between different refugee-related PTEs and mental ill health, as postmigration stress in this context is likely a potential mediator rather than a confounder.

To examine this assumption, the mediating role/function of postmigratory stressful experiences in the association between PTEs and mental ill health, mediation analyses were performed with number of included types of exposure for PTEs as exogenous, number of types of postmigratory stressful experiences as mediator and mental ill health as endogenous outcomes.

Bootstrapping with 1000 resamplings and Taylor linearised variance estimation ${ }^{28}$ were used to obtain $95 \%$ CIs for prevalence rates and ORs, respectively.

To explore potential bias from missing values, a series of sensitivity analyses were conducted using multiple imputation by chained equations (MICE) ${ }^{29}$ in SPSS, an approach including a random component that is suitable when missing values are assumed to be missing at random (MAR). The applied MICE model included all categorical variables employed in the study as predictors.

To evaluate whether the cut-offs for mental ill health may have influenced the estimates, a second set of sensitivity analyses were conducted by rerunning all regression analyses while specifying the outcomes as continuous variables. As the outcomes had a non-normal distribution, a two-step approach was used to obtain more normally distributed variables. ${ }^{30}$

In a final set of sensitivity tests, all associations between postmigration stress and mental ill health were rerun where postmigration stressful experiences were defined more leniently (ie, having experienced the specified situation at least once since immigrated to Sweden as opposed to having experienced it often).

All analyses were conducted with SPSS V.24.0 except the mediation analyses that were performed in Mplus V.8.

\section{RESULTS}

Table 1 shows the distribution of sociodemographic characteristics among the survey participants and among the sample frame, together with the corresponding distribution after weighting for non-response. Table 1 also shows bivariate associations between the sociodemographic characteristics and non-response.

The non-response analysis revealed that younger, not married, less recently immigrated individuals and those with lower educational level were less likely to participate in the study. Women were, however, neither over-represented nor under-represented. When applying the non-response weights to the sample, the sociodemographic distribution corresponded closely with that of the sample frame, with the expectation that married individuals still were slightly over-represented.

\section{Prevalence rates of mental ill health}

Table 2 shows that it was estimated that $55.0 \%$ (95\% CI $52.0 \%$ to $58.0 \%$ ) of recently resettled refugees from Syria have at least one of the studied type of mental ill health. Depression was the most common type $40.2 \%$ (95\% CI $36.9 \%$ to $43.3 \%$ ), followed by low SWB $37.7 \%$ (95\% CI $34.8 \%$ to $40.1 \%$ ), anxiety $31.8 \%$ (95\% CI $29.2 \%$ to $34.7 \%$ ) and PTSD $29.9 \%$ (95\% CI $27.2 \%$ to $32.6 \%$ ). Sociodemographically stratified analyses showed that mental ill health generally were more common among women, with the possible exception of PTSD. The stratified estimates further showed that those in the oldest age category (ie, 50-64 years) had elevated rates of mental ill health, particularly with regard to PTSD. The prevalence rates of anxiety, depression and PTSD were similar across the three educational levels, while low SWB appeared to be more common among individuals with a higher level of education. Finally, it was shown that those who were divorced or had experienced the death of a spouse were more at risk for all the studied types of mental ill health. No difference in prevalence were detected when stratifying analyses by year of immigration, that is, highly overlapping CIs (data not shown).

Mental ill health comorbidity and binominal correlations Table 3 shows that the mental ill health comorbidity was substantial among the respondents. The different 
Table 1 Sociodemographic characteristics in percentage among respondents, the sample frame and the weighted sample, supplemented with non-response analysis

\begin{tabular}{|c|c|c|c|c|}
\hline & $\begin{array}{l}\text { Respondents } \\
(n=1215)\end{array}$ & $\begin{array}{l}\text { Sample frame } \\
(n=4000)\end{array}$ & $\begin{array}{l}\text { Weighted data } \\
\text { set }\end{array}$ & $\begin{array}{l}\text { Respondents versus } \\
\text { non-respondents } \\
\chi^{2} \text { (P values) }\end{array}$ \\
\hline Gender & & & & $0.4(0.52)$ \\
\hline Men & 62.8 & 63.5 & 63.5 & \\
\hline Women & 37.2 & 36.5 & 36.5 & \\
\hline Age groups (years) & & & & $68.7(<0.01)$ \\
\hline $18-29$ & 23.3 & 30.8 & 30.7 & \\
\hline 30-39 & 32.9 & 33.7 & 33.5 & \\
\hline $40-49$ & 24.3 & 21.0 & 21.0 & \\
\hline $50-64$ & 19.5 & 14.6 & 14.8 & \\
\hline Marital status & & & & $78.9(<0.01)$ \\
\hline Married & 63.5 & 52.9 & 57.5 & \\
\hline Unmarried & 31.8 & 40.8 & 38.0 & \\
\hline Divorced/widow/widower & 4.8 & 6.4 & 4.6 & \\
\hline Level of educational & & & & $47.2(<0.01)$ \\
\hline $0-9$ years & 40.2 & 46.4 & 47.0 & \\
\hline$>9$ years without a university degree & 21.0 & 22.3 & 22.0 & \\
\hline$>12$ years with a university degree & 38.7 & 31.5 & 31.0 & \\
\hline Year of immigration* & & & & $34.0(<0.01)$ \\
\hline$\leq 2011$ & 6.5 & 10.1 & 10.3 & \\
\hline 2012 & 27.5 & 29.5 & 29.3 & \\
\hline 2013 & 66.0 & 60.4 & 60.4 & \\
\hline
\end{tabular}

${ }^{*}$ This variable indicates the year the individual arrived to Sweden and should not be confused with year for being granted residency used as inclusion criteria.

measures of mental ill health overlap and correlate strongly. Some variations indicate that the measures capture partly different facets of mental ill health. The strongest correlations and comorbidities are found between depression and anxiety and between PTSD and depression, while the weakest relationship is found between low SWB and anxiety.

\section{Refugee-related potentially traumatic premigratory and perimigratory events and their associations with mental ill health}

Table 4 shows that potentially traumatic events experienced before or during migration were very common among the resettled refugees from Syria. A total of $85 \%$ report experiencing war at close quarters and $79 \%$ reported being exposed to other frightening (life-threatening) situations. The majority also reported forced separation from family or close friends $(67.9 \%)$ and loss of a significant other (64\%). A large proportion had witnessed violence or assault (63\%), a third report having experienced physical violence or assault and a similar proportion reported that they had been subjected to torture $(31.0 \%)$. Seven per cent report being subjected to sexual violence. On average, the refugees from Syria reported that they had experienced $4.2(4.1-4.3)$ of the eight studied types of PTEs before or during the migration. When calculating these means separately for the premigration and the perimigration periods, they were $4.0(3.9-4.1)$ and 2.1 (2.0-2.2), respectively.

The results presented in table 4 further show that all types of investigated refugee related PTEs were significantly $(\mathrm{P}<0.05)$ associated with all studied types of mental ill health (adjusted for sociodemographic factors). Overall, these adjusted associations appeared to be strongest in relation to PTSD and weakest in relation to low SWB. Being exposed to the different types of PTEs predicted anxiety and depression similarly, with the possible exception of sexual violence that appeared to be a stronger predictor of anxiety. It is, however, important to interpret differences with some caution given that the CIs are rather wide and overlapping.

\section{Postmigration stressful experiences and their associations with mental ill health}

In table 5, it is shown to what extent the respondents report repeated postmigration stressful experiences and how these are associated with mental ill health, when adjusting for sociodemographic factors and premigratory and/or perimigratory PTEs. Of the investigated types of postmigration stress, often missing social life from back home 
Table 2 Prevalence of anxiety, depression, low SWB, PTSD or any in total and among subpopulations with $95 \% \mathrm{Cls}^{*}$

\begin{tabular}{|c|c|c|c|c|c|}
\hline & $\begin{array}{l}\text { Anxiety } \\
\%(95 \% \mathrm{Cl})\end{array}$ & $\begin{array}{l}\text { Depression } \\
\%(95 \% \mathrm{Cl})\end{array}$ & $\begin{array}{l}\text { Low SWB } \\
\%(95 \% \mathrm{Cl})\end{array}$ & $\begin{array}{l}\text { PTSD } \\
\%(95 \% \mathrm{Cl})\end{array}$ & $\begin{array}{l}\text { Any† } \\
\%(95 \% \mathrm{Cl})\end{array}$ \\
\hline Total (weighted) & 31.8 (29.2 to 34.7$)$ & 40.2 (36.9 to 43.3 ) & 37.7 (34.8 to 40.1 ) & 29.9 (27.2 to 32.6$)$ & 55.0 (52.0 to 58.0$)$ \\
\hline Total (unweighted) & 31.6 (29.1 to 34.3$)$ & 40.6 (37.8 to 43.2 ) & 38.3 (35.6 to 41.2 ) & 30.6 (28.0 to 33.4$)$ & 55.6 (52.7 to 58.5$)$ \\
\hline \multicolumn{6}{|l|}{ Gender } \\
\hline Men & 27.7 (24.2 to 31.1$)$ & 37.9 (34.1 to 41.7$)$ & 33.1 (31.4 to 38.9 ) & 29.0 (25.5 to 32.9$)$ & 51.3 (47.1 to 55.0$)$ \\
\hline Women & 38.8 (34.1 to 43.7$)$ & 44.1 (39.6 to 48.8 ) & 42.2 (37.0 to 47.1$)$ & 31.3 (26.8 to 35.7$)$ & 61.3 (56.6 to 66.0 ) \\
\hline \multicolumn{6}{|l|}{ Age groups (years) } \\
\hline $18-29$ & 31.5 (25.9 to 37.4$)$ & 38.3 (32.6 to 44.4 ) & 36.4 (30.6 to 42.7 ) & 25.6 (20.2 to 30.9$)$ & $54.2(48.0$ to 60.1$)$ \\
\hline 30-39 & 26.2 (21.8 to 30.8$)$ & 36.2 (31.4 to 41.2 ) & 37.0 (32.2 to 41.9$)$ & 27.2 (22.6 to 31.9 ) & 50.3 (45.0 to 55.5$)$ \\
\hline $40-49$ & $34.2(28.1$ to 40.1$)$ & 41.5 (36.0 to 47.0$)$ & 35.7 (30.0 to 41.7 ) & 30.2 (24.9 to 35.9 ) & 55.7 (50.1 to 61.6$)$ \\
\hline $50-64$ & 41.9 (35.4 to 48.8$)$ & 51.1 (44.5 to 63.8$)$ & 45.2 (38.1 to 51.9 ) & 44.7 (37.8 to 51.3 ) & 65.9 (59.5 to 72.6$)$ \\
\hline \multicolumn{6}{|l|}{ Level of education } \\
\hline $0-9$ years & 33.5 (29.2 to 38.0$)$ & 38.9 (34.5 to 43.5$)$ & 34.3 (29.5 to 38.8$)$ & 30.6 (26.5 to 35.3$)$ & $54.2(49.2$ to 59.1$)$ \\
\hline $\begin{array}{l}>9 \text { years without a } \\
\text { university degree }\end{array}$ & 29.8 (24.0 to 36.2 ) & 41.7 (35.2 to 47.5$)$ & 35.8 (29.3 to 42.3 ) & 30.8 (24.8 to 81.2$)$ & 53.4 (47.5 to 60.6$)$ \\
\hline $\begin{array}{l}>12 \text { years with a } \\
\text { university degree }\end{array}$ & 30.6 (26.3 to 35.1$)$ & 40.9 (36.4 to 45.9$)$ & 44.2 (39.3 to 48.9$)$ - & 28.1 (24.1 to 32.5$)$ & 56.8 (52.1 to 61.5$)$ \\
\hline \multicolumn{6}{|l|}{ Marital status } \\
\hline Married & $30.9(27.4$ to 34.0$)$ & 37.9 (34.4 to 41.6$)$ & 35.9 (32.3 to 39.5$)$ & 27.3 (24.1 to 30.7$)$ & 52.9 (49.2 to 56.6$)$ \\
\hline Unmarried & 30.9 (26.2 to 35.9$)$ & 41.6 (36.5 to 46.8$)$ & 39.0 (33.4 to 44.3 ) & 31.3 (26.7 to 36.3 ) & 55.9 (50.5 to 61.2$)$ \\
\hline $\begin{array}{l}\text { Divorced/widow } \\
\text { /widower }\end{array}$ & 51.8 (38.0 to 66.1 ) & 56.5 (41.9 to 69.5$)$ & 50.0 (36.1 to 62.3$)$ & 51.5 (37.9 to 65.1$)$ & 72.8 (60.9 to 84.8$)$ \\
\hline
\end{tabular}

Anxiety: $n=1185$, depression: $n=1203$, low SWB: $n=1180$, PTSD: $n=1153$, any: $n=1172$.

${ }^{*}$ All prevalence rates among subpopulations are weighted. 95\% Cls are calculated based on robust standard errors.

†Anxiety, depression, low SWB or PTSD.

PTSD, post-traumatic stress disorder; SWB, subjective well-being.

and often feeling sad because not reunited with family members were the most common ones, experienced by a majority. Around $20 \%$ of the respondents reported that they had often felt excluded or isolated in Sweden, while less than $10 \%$ indicated that they had often experienced ethnic discrimination, extreme poverty or distressing family conflicts after resettlement in Sweden.

All seven postmigratory stressful experiences were significantly associated with anxiety, depression, low SWB and PTSD, with the exception of often sad due to not being

Table 3 Proportions with different concurrent mental ill health comorbidities with 95\% Cls and binominal correlations $(\varphi)^{\star}$

\begin{tabular}{|c|c|c|c|c|}
\hline & $\begin{array}{l}\text { Concurrent anxiety } \\
\%(95 \% \mathrm{Cl})\end{array}$ & $\begin{array}{l}\text { Concurrent depression } \\
\%(95 \% \mathrm{Cl})\end{array}$ & $\begin{array}{l}\text { Concurrent low SWB } \\
\%(95 \% \mathrm{Cl})\end{array}$ & $\begin{array}{l}\text { Concurrent } \\
\text { PTSD } \\
\%(95 \% \text { Cl) }\end{array}$ \\
\hline Anxiety & 100 & 86.6 (83.1 to 90.0$)$ & 68.7 (63.9 to 73.5$)$ & 67.3 (62.4 to 72.2$)$ \\
\hline Depression & 70.0 (65.9 to 74.2$)$ & 100 & 71.0 (66.9 to 76.3$)$ & 68.0 (62.4 to 80.8 ) \\
\hline Low SWB & 58.2 (53.5 to 62.8$)$ & 75.4 (71.4 to 79.4$)$ & 100 & 61.3 (56.6 to 65.9$)$ \\
\hline PTSD & 73.0 (68.3 to 77.8$)$ & 90.0 (86.8 to 93.1$)$ & 77.5 (73.1 to 81.9$)$ & 100 \\
\hline \multicolumn{5}{|c|}{ Binominal correlations } \\
\hline & Anxiety $\varphi$ & Depression $\varphi$ & Low SWB $\varphi$ & PTSD $\varphi$ \\
\hline Anxiety & 1 & & & \\
\hline Depression & 0.66 & 1 & & \\
\hline Low SWB & 0.44 & 0.56 & 1 & \\
\hline PTSD & 0.57 & 0.67 & 0.52 & 1 \\
\hline
\end{tabular}

${ }^{*}$ All analyses are weighted, and $95 \% \mathrm{Cl}$ are calculated based on robust standard errors.

PTSD, post-traumatic stress disorder; SWB, subjective well-being. 


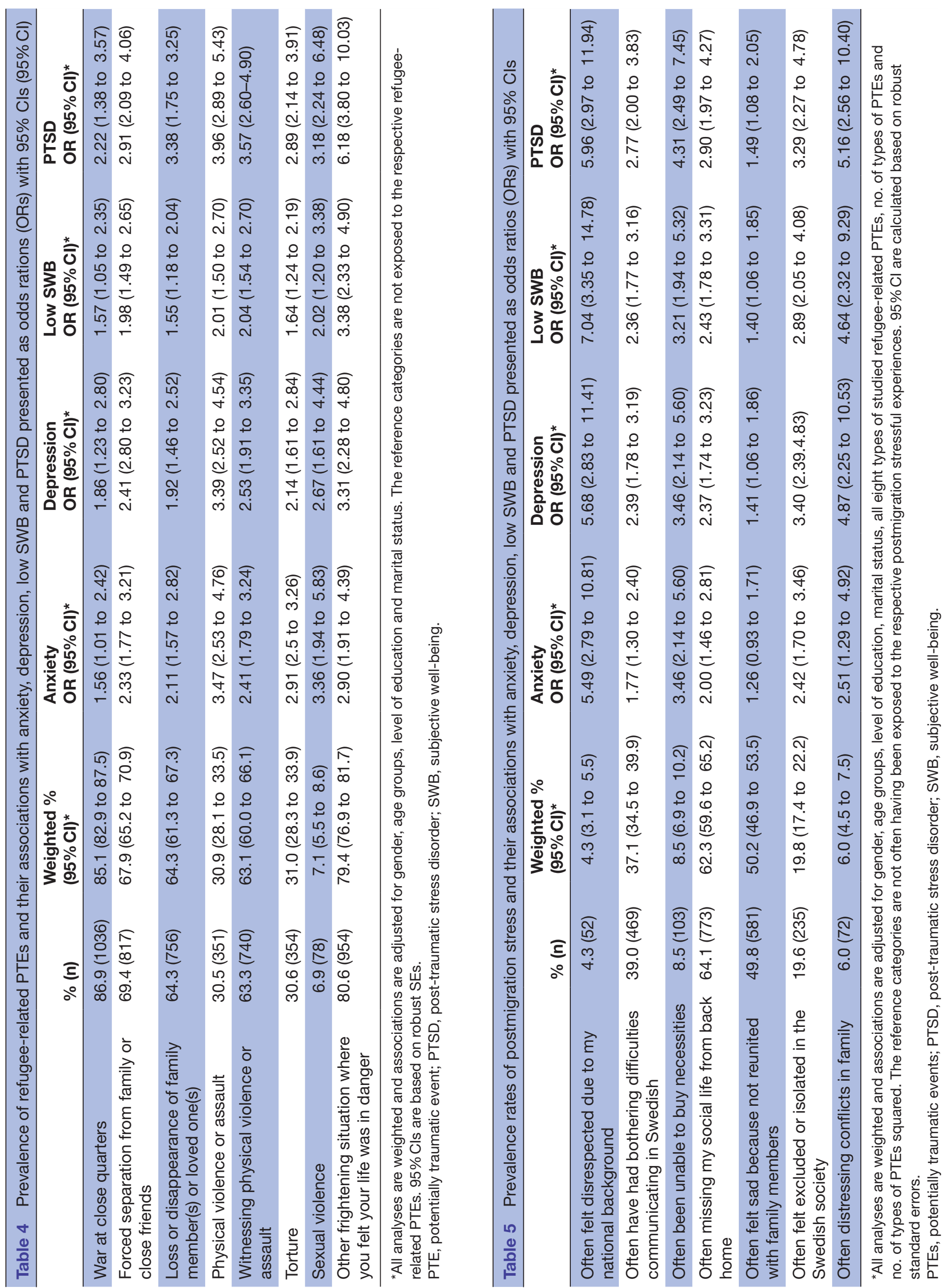


Table 6 Estimates of direct effect of number of types of PTE exposures, and indirect effect of number of types of postmigratory stressful experiences modelled as mediator, with mental ill health as outcome*

\begin{tabular}{|c|c|c|c|c|c|c|}
\hline & \multicolumn{3}{|c|}{ Direct effect } & \multicolumn{3}{|c|}{ Indirect effect } \\
\hline & Estimate & SE & $95 \% \mathrm{Cl}$ & Estimate & SE & $95 \% \mathrm{Cl}$ \\
\hline Anxiety & 0.044 & 0.006 & 0.031 to 0.056 & 0.013 & 0.002 & 0.009 to 0.019 \\
\hline Depression & 0.045 & 0.007 & 0.032 to 0.058 & 0.017 & 0.003 & 0.012 to 0.023 \\
\hline Low SWB & 0.024 & 0.007 & 0.011 to 0.037 & 0.017 & 0.003 & 0.012 to 0.023 \\
\hline PTSD & 0.056 & 0.006 & 0.044 to 0.068 & 0.017 & 0.003 & 0.012 to 0.022 \\
\hline
\end{tabular}

${ }^{*}$ Estimates are unstandardized with corresponding bias-corrected bootstrapped (Cls) and robust standard errors (SE).

PTE, potentially traumatic event.

reunited with family members, which was not significantly associated with anxiety (table 5). Often felt disrespected due to my national background seemed to be the type of postmigration stressful experience that predicted mental ill health most strongly, while often felt sad because not reunited with family members generally exhibited the weakest association with mental ill health. Even though interpretations should be made with cautions, as the CIs in most cases are highly overlapping, the result indicates that postmigration stress is stronger related to PTSD than it is to anxiety.

The results presented in table 6 reveal that number of types of postmigratory stressful experiences partially mediated the effect of PTEs on all the included mental ill health outcomes.

\section{Sensitivity analyses}

The sensitivity analyses showed result similar to the main analysis (See online supplementary material 1-6). The prevalence rates were approximately the same in the multiple imputed datasets (supplementary material 1) and associations that were significant $(\mathrm{P}<0.05)$ or non-significant in the main analyses remained so in almost all the sensitivity analyses (supplementary material 2-6). One exception was that felt sad because not reunited with family members was no longer a significant predictor of any mental ill health measures when operationalized more leniently.

\section{DISCUSSION}

This study, one of the first of its kind, indicate that refugees from Syria that resettled in Sweden following the war that started in 2011 have prevalence rates of anxiety, depression, low subjective well-being and PTSD that range between $30 \%$ and $40 \%$. A majority reported symptoms in line with at least one of these four types of mental ill health, and many fulfilled multiple criteria. Mental ill health was generally more common among women, older and the divorced or widowed refugees. The study further showed that refugee-related potentially traumatic events and post-migration stress were common. For example, $30 \%$ reported they had experienced torture, while $50 \%$ often had been sad because not being reunited with family members. Finally, it was revealed that practically all investigated types of refugee related PTEs and postmigration stress were significantly associated with anxiety, depression, low SWB and PTSD.

The prevalence rates in this study are in line with many others obtained from previous larger studies on refugees. ${ }^{331} 32$ Any comparison should, however, be done with caution given that the contexts, methodological aspects and the inclusion criteria usually vary extensively between studies. Nonetheless, some previous findings are more reasonable to contrast with our reported prevalence estimates as both pre- and post-migration conditions exhibit several similarities. A smaller Swedish study among Iraqi asylum seekers aged $18-48$ years in which the prevalence of PTSD was estimated to $38 \%$ is one of those, ${ }^{33}$ while Laban $e t a l^{34}$ study among Iraqi asylum seekers in the Netherlands, where the prevalence of anxiety syndrome was estimated to $22 \%$, depression to $34 \%$ and PTSD to $36 \%$, is another such example. These more comparable prevalence estimates are thus similar with those reported here among recent refugees from Syria resettled in Sweden. Moreover, in two recent studies on Syrian refugees living in refugee camps in Turkey and Lebanon the prevalence of PTSD was estimated to around 30 percent $^{3536}$

In Bogic et al review article it was revealed that mental ill health appear to be particularly common among refugees from former Yugoslavia or Cambodia and among refugees resettled in the US. The prevalence rates reported here are generally lower than those reported among Cambodians in $\mathrm{US}^{37}$ (at least with regard to depression), but comparable to estimates among refugees from former Yugoslavia resettled in different parts of Europe. ${ }^{32}$ The high rates of mental ill health among the Syrian refugees are probably most appropriately interpreted in light of the high exposure to war-related PTEs described in the present article and the sheer magnitude of human rights violation during the Syrian conflict. ${ }^{38}$

It is difficult to establish the extent of applicability of the mental ill health prevalence from this study to Syrian refugee populations resettled in other European countries. However, as long as post-migration conditions and differences in immigration legislation or asylum policies at the resettlement destination do no distort comparability, these estimates are likely to be transferable to a large degree. In this regard, it should be emphasised that time passed since resettlement may also influence 
transferability of the prevalence estimates, since the adverse effects of war-related PTEs as well as post-migration stress tend to diminish with time..$^{39} 40$

That mental ill health is more common among women, older and divorced/widowed refugees are consistent with other research. ${ }^{3} 1932$ These associations are commonly also observed in non-refugee populations. However, the finding that mental ill health does not appeared to differ by educational level may seem surprising, but this has also been observed previously among refugees in Sweden. ${ }^{19}$ Studies investigating this association among refugees have nonetheless reported contradictory findings, ${ }^{20} 32$ which is likely to be attributable (at least partially) to differences between refugee populations and the post-migration conditions. A possible explanation on a more theoretical level may be that the buffering effect of higher education (or buffering effects related to higher education) is cancelled out as a result of that refugees with a higher educational level experience greater loss of status. Loss of status, or downward social mobility as it also sometimes is called, has been shown to have an adverse effect on refugees' mental health. $^{41}$

All eight, deliberately broad, categories of pre- and peri-migratory refugee-related PTEs were related to mental ill health. This clearly demonstrates that many types of refugee-related PTEs are associated with different manifestations of mental ill health. Still, it was revealed that the refugee-related PTEs were stronger predictors for PTSD than for low SWB. Overall, and in line with previous findings, the PTEs that showed the strongest associations with mental ill health were those that involved exposure to interpersonal violence. ${ }^{42}$

A somewhat puzzling exception is that torture appears to have the weakest association with low SWB among the studied PTEs. This may be because individuals tend to value their current life as less negative, all else being equal, when having experienced harsh former living conditions. ${ }^{43}$ The reported associations between refugee related PTEs' and mental ill health are most likely causal in nature, as it seems unreasonable to propose that individuals with mental ill health would be more at risk for refugee related PTEs. Neither does previous research support that under-reporting of PTEs are more common among refugees without mental ill health. It is, if something, more likely that individuals with mental ill health are more prone to under-report PTEs, ${ }^{44}$ which would suggest that the associations presented between refugee related PTEs and mental ill health are underestimated rather than overestimated.

The study further showed that all included types of post-migration stress were significantly associated with mental ill health, when adjusting for refugee-related PTEs. Similar findings have been shown in previous research among other refugee or migrant populations ${ }^{18} 1945$ which corroborate our expectations. A notable exception was that feeling sad because not reunited with family members' association with mental ill health was not substantiated in some of the sensitivity analyses. These non-associations were primarily detected in the sensitivity analyses where a very lenient cut-off was used, that is, feeling sad because not reunited with family members at least once since immigrated to Sweden. Such low thresholds for endorsing this statement may perhaps indicate less severe emotional distress, which could explain the lack of substantial association with mental ill health. Furthermore, not being united with one's family could be viewed as a proxy for lack of an important source of social support ${ }^{46}$ which is strongly associated with mental health. ${ }^{47}$ The displayed weak association in the present study contradicts both clinical practice and previous findings. An explanation may also be that some respondents have interpreted family in a wider sense including distant relatives. If this is the case, which is not entirely unlikely, it would imply that the item is a suboptimal proxy of social support.

That the association between refugee-related PTEs and mental ill health appears to be partially mediated by postmigration stress is an important finding that deserves to be investigated in more detail. This observation nonetheless indicates that exposure to PTEs make refugees particularly susceptible to adverse stressful experiences during resettlement. Whether this is to be attributed to that PTEs reduce refugees' coping resources or that refugee-related PTEs make individuals more likely to become exposed to difficult situations, or both, remains unclear. Nickerson et $a t^{49}$ found in their cross-sectional study among refugees resettled in Switzerland that difficulties in regulating emotions meditated the association between trauma exposure and mental ill health almost completely, while it partially mediated the association between postmigration stress and PTSD, and depression. Emotion dysregulation may thus be an essential causal mechanism for explaining also the findings reported in the present study.

Postmigration stress and mental ill health are on the other hand likely to be reciprocally associated. ${ }^{16}$ It has been reported that refugees with PTSD tend to have greater difficulties to learn the language spoken at the resettlement destination ${ }^{50}$, and that refugees with mental ill health tend to interpret adverse events as being more stressful, while simultaneously evaluating favourable life events as less positive. ${ }^{51}$ Without onset information, it is possible that residual confounding may to some extent have distorted the associations between postmigration stress and mental ill health. Another potential source of residual confounding between specific postmigration stress and mental ill health comes from not adjusting for other types of postmigration stress, which was a deliberate choice in order to avoid over adjustment. What nonetheless can be concluded is that these associations are not confounded by refugee-related PTEs nor a consequence of reverse causation, as refugee-related PTEs predate postmigration stress and are adjusted for.

\section{Strength and limitations}

This is the first larger comprehensive study of mental ill health among recently resettled refugees from Syria in a European country. That the study is based on a random 
sample drawn from a known sample frame including all eligible participants is a major and unique strength. The availability of the register-based information for all eligible study participants enabled us to evaluate the representativeness of our sample. It also provided the opportunity to construct non-response weights for obtaining more reliable estimates even though the non-response rate is substantial.

All the same, the substantial non-response rate poses the single greatest limitation of the study. It has previously been indicated in a Swedish study that prevalence estimates of mental ill health are likely biased, in a downward direction, as a consequence of that mental ill health tend to be more common among non-respondents. ${ }^{52}$ Whether this finding also is applicable for mental health surveys targeting refugees from Syria is not known. However, the weighted and unweighted prevalence rates of mental ill health were similar, and provided some support for that this type of selection bias may be negligible in this case.

The use of several different measures of mental ill health, all with high internal consistency, is also a strength. All employed measures of mental ill health have frequently been used and shown to exhibit good psychometric properties in diverse cultural settings. ${ }^{23-27}$ The robustness of our results are supported by the fact that all of these outcomes when analysed, dichotomized or continuous, provided similar findings. That being said, the cut-offs used in the present study have not yet been validated among refugees from Syria. The cut-offs used in the present study are based on validation studies among other war-tormented populations, but further studies are needed to substantiate the appropriateness of employing them also in this context.

Another limitation of this study is the use of self-report data in the assessment of mental ill health. Although clinical interviews may hold stronger validity, the possibility of conducting such interviews in large scale studies and among the hard to reach population of the refugees are inevitably constrained for logistic and practical reasons. Moreover, it should be emphasised that the single items used to identify different war-related PTEs and types of post-migration stress neither capture nor include all factors that are likely to be of importance in this context. Nonetheless, the included items cover a broad range of aspects that according to previous research have been shown to be associated with mental ill health among refugees.

Cross-sectional studies are well suited for estimating prevalence, while making causal claims based on cross-sectional data should be done with extreme caution-if it is at all reasonable to make such claims. Caution when interpreting the current findings in terms of causality is thus warranted. We advocate, however, that PTEs can be accurately assessed retrospectively, and are likely to precede the mental ill health and thus possible to be studied using a cross-sectional design. To better understand associations between postmigration stress and mental ill health prospective studies are needed, which currently are rare among refugee populations.

\section{CONCLUSION}

Our study shows that prevalence of mental ill health, in terms of anxiety, depression, low subjective well-being and PTSD, is highly elevated and comorbid among refugees from Syria. Moreover, refugee-related PTEs as well as postmigration stress are associated to several different manifestations of mental ill health. Increased attention from multiple societal sectors, the governmental and healthcare sector in particular, to adequately support Syrian refugees' mental health needs, promote their recovery and reduce post-migration stress are needed. The results further indicate that healthcare workers should not only focus on treatment related to previous PTEs, but also support refugees in their efforts to dampen the adverse effects of postmigration stress. Also more prospective and population-based research are warranted to better understand the causal mechanisms involved.

Contributors PT and FS conceptualised and designed the study and the empirical analyses. FS obtained the funding. PT, CA and AM collected the data. PT, AM, CA, ES and FS constructed and/or adapted the questionnaire. ES had a special responsibility with research issues dealing with potentially traumatic events, while AM had the same type of responsibility regarding postmigration stress. PT conducted the statistical analyses with advice and support from AL and FS. PT drafted the initial version of the manuscript. All authors contributed in revising and editing the manuscript with substantial methodological and intellectual support and approved the manuscript as submitted. PT and FS are the guarantors of the study.

Funding This study was supported by Swedish Research Council for Health, Working Life and Welfare (grant number 2016-07194), the Swedish Ministry of Employment, with additional financial support from the Swedish Red Cross and the Swedish Red Cross University College.

Disclaimer The funders had no role in study design, data analysis, decision to publish or preparation of manuscript.

\section{Competing interests None declared.}

Ethics approval The study was approved by the Stockholm Regional Ethical Review Board (number: 2015/1463-1431 and 2016/549-32).

Provenance and peer review Not commissioned; externally peer reviewed.

Data sharing statement The statistical code is available from the corresponding author. Under Swedish law and ethical approval, individual level data of this kind cannot be publicly available. Individual level data can be made available on reasonable request as long as it is in line with Swedish law and ethical approvals.

Open Access This is an Open Access article distributed in accordance with the Creative Commons Attribution Non Commercial (CC BY-NC 4.0) license, which permits others to distribute, remix, adapt, build upon this work non-commercially, and license their derivative works on different terms, provided the original work is properly cited and the use is non-commercial. See: http://creativecommons.org/ licenses/by-nc/4.0/

(c) Article author(s) (or their employer(s) unless otherwise stated in the text of the article) 2017. All rights reserved. No commercial use is permitted unless otherwise expressly granted.

\section{REFERENCES}

1. UNHCR. Figures at a glance. 2017. http://www.unhcr.org/figures-ata-glance.html (accessed Jun 20 2017).

2. Center MP. Syrian refugees: a snapshot of the crisis-in the middle East and Europe 2014. 2016. http://syrianrefugees.eu (accessed 20 Jul 2017). 
3. Bogic M, Njoku A, Priebe S. Long-term mental health of warrefugees: a systematic literature review. BMC Int Health Hum Rights $2015 ; 15: 29$

4. Fazel M, Wheeler J, Danesh J. Prevalence of serious mental disorder in 7000 refugees resettled in western countries: a systematic review. Lancet 2005;365:1309-14.

5. Miller KE, Rasmussen A. The mental health of civilians displaced by armed conflict: an ecological model of refugee distress. Epidemiol Psychiatr Sci 2017;26:129-38.

6. Mollica RF, Poole C, Son L, et al. Effects of war trauma on Cambodian refugee adolescents' functional health and mental health status. J Am Acad Child Adolesc Psychiatry 1997;36:1098-106.

7. Lindencrona F, Ekblad S, Hauff E. Mental health of recently resettled refugees from the Middle East in Sweden: the impact of preresettlement trauma, resettlement stress and capacity to handle stress. Soc Psychiatry Psychiatr Epidemiol 2008;43:121-31.

8. Miller KE, Rasmussen A. War exposure, daily stressors, and mental health in conflict and post-conflict settings: bridging the divide between trauma-focused and psychosocial frameworks. Soc Sci Med 2010;70:7-16.

9. Steel Z, Chey T, Silove D, et al. Association of torture and other potentially traumatic events with Mental health outcomes among populations exposed to mass conflict and Displacement. JAMA 2009;302:537.

10. Carlson EB, Rosser-Hogan R. Trauma experiences, posttraumatic stress, dissociation, and depression in Cambodian refugees. Am J Psychiatry 1991;148:1548.

11. Priebe S, Bogic M, Ajdukovic D, et al. Mental disorders following war in the Balkans: a study in 5 countries. Arch Gen Psychiatry 2010;67:518-28.

12. Arsenijević J, Schillberg E, Ponthieu A, et al. A crisis of protection and safe passage: violence experienced by migrants/refugees travelling along the Western Balkan corridor to Northern Europe. Confl Health 2017;11:6.

13. Wong ST, Yoo GJ, Stewart AL. An empirical evaluation of social support and psychological well-being in older Chinese and Korean immigrants. Ethn Health 2007;12:43-67.

14. Bhugra D, Ayonrinde O. Depression in migrants and ethnic minorities. Adv Psychiatr Treat 2004;10:13-17.

15. Pascoe EA, Smart Richman L. Perceived discrimination and health: a meta-analytic review. Psychol Bull 2009;135:531-54.

16. Beiser M, Hou F. Language acquisition, unemployment and depressive disorder among Southeast Asian refugees: a 10-year study. Soc Sci Med 2001;53:1321-34.

17. Carta MG, Bernal M, Hardoy MC, et al. Migration and mental health in Europe (the state of the mental health in Europe working group: appendix 1). Clin Pract Epidemiol Ment Health 2005;1:13.

18. Laban CJ, Gernaat HB, Komproe IH, et al. Postmigration living problems and common psychiatric disorders in Iraqi asylum seekers in the Netherlands. J Nerv Ment Dis 2005:193:825-32.

19. Tinghög P, Al-Saffar S, Carstensen J, et al. The association of immigrant- and non-immigrant-specific factors with mental ill health among immigrants in Sweden. Int J Soc Psychiatry 2010;56:74-93.

20. Porter M, Haslam N. Predisplacement and postdisplacement factors associated with mental health of refugees and internally displaced persons: a meta-analysis. JAMA 2005;294:602-12.

21. Drennan J. Cognitive interviewing: verbal data in the design and pretesting of questionnaires. J Adv Nurs 2003;42:57-63.

22. Sigvardsdotter E, Nilsson $\mathrm{H}$, Malm A, et al. Development and preliminary validation of refugee trauma history checklist (RTHC)-A brief checklist for survey studies. Int J Environ Res Public Health 2017:14:1175.

23. Hollifield M, Warner TD, Lian N, et al. Measuring trauma and health status in refugees: a critical review. JAMA 2002;288:611-21.

24. Tinghög P, Carstensen J. Cross-cultural equivalence of HSCL-25 and WHO (ten) Wellbeing index: findings from a population-based survey of immigrants and non-immigrants in Sweden. Community Ment Health J 2010;46:65-76.

25. Oruc L, Kapetanovic A, Pojskic N, et al. Screening for PTSD and depression in Bosnia and Herzegovina: validating the Harvard Trauma Questionnaire and the Hopkins Symptom Checklist. Int $J$ Cult Ment Health 2008;1:105-16.

26. Mollica RF, Wyshak G, de Marneffe D, et al. Indochinese versions of the Hopkins Symptom Checklist-25: a screening instrument for the psychiatric care of refugees. Am J Psychiatry 1987;144:497-500.

27. Topp CW, Østergaard SD, Søndergaard S, et al. The WHO-5 Well-Being Index: a systematic review of the literature. Psychother Psychosom 2015;84:167-76.
28. Wolter K. Introduction to variance estimation: Springer Science \& Business Media, 2007.

29. White IR, Royston P, Wood AM. Multiple imputation using chained equations: Issues and guidance for practice. Stat Med 2011;30:377-99.

30. Templeton GF. A two-step approach for transforming continuous variables to normal: implications and recommendations for IS research. CAIS 2011;28:4.

31. Sigvardsdotter E, Vaez M, Rydholm Hedman AM, et al. Prevalence of torture and other warrelated traumatic events in forced migrants: A systematic review. Torture 2016;26:41-53.

32. Bogic M, Ajdukovic D, Bremner S, et al. Factors associated with mental disorders in long-settled war refugees: refugees from the former Yugoslavia in Germany, Italy and the UK. Br J Psychiatry 2012;200:216-23.

33. Söndergaard HP, Ekblad S, Theorell T. Screening for post-traumatic stress disorder among refugees in Stockholm. Nord $J$ Psychiatry 2003;57:185-9.

34. Laban CJ, Gernaat HB, Komproe IH, et al. Impact of a long asylum procedure on the prevalence of psychiatric disorders in Iraqi asylum seekers in The Netherlands. J Nerv Ment Dis 2004;192:843-51.

35. Alpak G, Unal A, Bulbul F, et al. Post-traumatic stress disorder among Syrian refugees in Turkey: a cross-sectional study. Int $J$ Psychiatry Clin Pract 2015;19:45-50.

36. Kazour F, Zahreddine NR, Maragel MG, et al. Post-traumatic stress disorder in a sample of Syrian refugees in Lebanon. Compr Psychiatry 2017;72:41-7.

37. Mollica RF, Mclnnes K, Poole C, et al. Dose-effect relationships of trauma to symptoms of depression and post-traumatic stress disorder among Cambodian survivors of mass violence. $\mathrm{Br} J$ Psychiatry 1998:173:482-8.

38. Watch HR. World report 2017 - events of 2016. New York: Human Rights Watch, 2017

39. Steel Z, Silove D, Phan T, et al. Long-term effect of psychological trauma on the mental health of Vietnamese refugees resettled in Australia: a population-based study. Lancet 2002;360:1056-62.

40. Beiser M. Influences of time, ethnicity, and attachment. Am J Psychiat 1988;1:46-51.

41. Das-Munshi J, Leavey G, Stansfeld SA, et al. Migration, social mobility and common mental disorders: critical review of the literature and meta-analysis. Ethn Health 2012;17:17-53.

42. Steel Z, Chey T, Silove D, et al. Association of torture and other potentially traumatic events with mental health outcomes among populations exposed to mass conflict and displacement: a systematic review and meta-analysis. JAMA 2009;302:537-49.

43. Rogler LH, Cortes DE, Malgady RG. Acculturation and mental health status among Hispanics: Convergence and new directions for research: American Psychological Association, 1991.

44. Mollica RF, Caridad KR, Massagli MP. Longitudinal study of posttraumatic stress disorder, depression, and changes in traumatic memories over time in Bosnian refugees. J Nerv Ment Dis 2007;195:572-9

45. Davidson GR, Murray KE, Schweitzer R. Review of refugee mental health and wellbeing: Australian perspectives. Aust Psychol 2008;43:160-74.

46. Taylor SE. Social support: A review. The handbook of health psychology 2011;189:214.

47. Kawachi I, Berkman LF. Social ties and mental health. J Urban Health 2001;78:458-67.

48. Schweitzer R, Melville F, Steel Z, et al. Trauma, post-migration living difficulties, and social support as predictors of psychological adjustment in resettled Sudanese refugees. Aust N Z J Psychiatry 2006;40:179-87.

49. Nickerson A, Bryant RA, Schnyder U, et al. Emotion dysregulation mediates the relationship between trauma exposure, post-migration living difficulties and psychological outcomes in traumatized refugees. J Affect Disord 2015:173:185-92.

50. Söndergaard HP, Theorell T. Language acquisition in relation to cumulative posttraumatic stress disorder symptom load over time in a sample of re-settled refugees. Psychother Psychosom 2004;73:320-3

51. Söndergaard HP, Ekblad S, Theorell T. Self-reported life event patterns and their relation to health among recently resettled Iraq and Kurdish refugees in Sweden. J Nerv Ment Dis 2001;189:838-45.

52. Lundberg I, Damström Thakker K, Hällström T, et al. Determinants of non-participation, and the effects of non-participation on potential cause-effect relationships, in the PART study on mental disorders. Soc Psychiatry Psychiatr Epidemiol 2005;40:475-83. 